\title{
FACULTY SELF-STUDY RESEARCH PROJECT: EXAMINING THE ONLINE WORKLOAD
}

\author{
Melody M. Thompson \\ Email: $\underline{\text { mmt2@psu.edu }}$ \\ Director, Quality \& Planning, Penn State World Campus and \\ Director, American Center for the Study of Distance Education \\ The Pennsylvania State University \\ 108 Rackley Building \\ University Park, PA 16802
}

814-865-5856

\begin{abstract}
Concerns about faculty workload in the online environment are a reported deterrent to participation in online teaching. To date, such concerns have been based primarily on anecdotal evidence rather than empirical research. This paper describes a project in which six faculty members teaching courses through the Penn State World Campus conducted studies of the comparative workload in the online environment. Results of the studies indicated that faculty workload for teaching these online courses, as measured by time on task, was comparable to or somewhat less than that for face-to-face courses. However, a differential "chunking" of productive time contributed in some cases to a perception of increased workload. The success of the project suggests it is a replicable model for investigating various elements of the faculty experience in the online environment.
\end{abstract}

\section{KEY WORDS}

Faculty workload, online teaching, faculty attitudes, faculty satisfaction

\section{INTRODUCTION}

A major determinant in the success of online higher education is a strong faculty commitment to teaching in this new environment, and a growing body of literature portrays the online teaching and learning environment as a personally rewarding and satisfying one for many faculty members [1, 2, 3, 4]. Thompson [5] discusses a number of specific positive factors reported by faculty members teaching online, including

- Increased access to/by students

- Increased opportunities for high-quality interaction with students

- Flexibility and convenience of teaching and learning

- Increased knowledge of and experience with educational technologies

- Opportunities for research and professional recognition

- Positive student outcomes

These outcomes have made online teaching a satisfying addition or alternative to traditional instruction for many faculty members. However, online faculty members have also reported some potential barriers 
to their participation in and satisfaction with online teaching. Two of the most frequently mentioned barriers are a widespread perception of increased workload and the related concern that an increased workload takes time from activities more highly regarded by the institution, specifically research and publication. With few exceptions [e.g., 6], the literature reports that distance teaching is more time intensive than face-to-face resident teaching [7, 2, 8, 3, 4]. This perception is reported to be a major deterrent to participation by those faculty members who can "opt out," and an inhibitor to satisfaction among those who have no choice or who choose to teach at a distance even given the perceived increased demands $[9,10,11]$.

Ensuring the commitment of the increasing numbers of faculty members necessary to maintain and expand online programming depends on appropriate responses to these concerns and the barriers they represent. However, the perception of increased workload has been based almost completely on anecdotal evidence, and the little empirical evidence available is conflicting, making establishment of appropriate institutional support and policy difficult. As a first step in addressing this challenge, the Penn State World Campus supported faculty researchers in answering some of the basic questions related to workload in the online environment.

\section{PROJECT OVERVIEW}

\section{A. Objectives of the Project}

The faculty self-study project had two main objectives: 1) to better understand-as the basis for improving - the faculty experience in teaching online, particularly as it relates to workload; and 2) to provide faculty members an opportunity to contribute to improved practice within a framework recognized and rewarded by the institution (i.e., bringing in research funds and publication of results).

\section{B. Participants}

The World Campus Faculty Workload Research Team comprised six Penn State World Campus faculty members and a project coordinator (the author of this article). Faculty members represented five disciplines: instructional systems, agronomy, geography, English, and horticulture. In order to factor out the "learning curve" and its major impact on the workload of first-time online instructors, selection of researchers was limited to those who had taught the courses to be studied at least once prior to the beginning of the project.

\section{Project Description}

The approach taken was to fund small empirical research projects conducted by online faculty members. Through an RFP process developed and implemented by the project coordinator, six faculty members were selected to conduct studies of their experiences teaching online. Four of the researchers conducted studies that directly compared the categories of tasks and the time involved teaching and administering online courses to those of classroom versions of the same courses. Two other researchers evaluated the implications of specific course administration practices and instructional tool choices on course effectiveness, specifically in relation to instructional quality as reflected in levels of interaction. All six of the researchers strove to identify those tasks that consumed a disproportionate amount of faculty timeparticularly time taken away from actual teaching/learning interactions with students-as the basis for developing alternative and time-saving pedagogical and/or technological approaches to those tasks. At the conclusion of each research study the principal investigator submitted a report that included objective findings of time spent on various tasks, reflective analysis, and recommendations for improving the experience of online faculty members. 


\section{RESULTS}

\section{A. Project Outcomes}

The two project objectives were met. In relation to Objective 1, both the end-of-project reports submitted by the faculty researchers and an end-of-project survey conducted by the project coordinator indicated that all of the research participants gained a better understanding of their workload in the online environment, particularly (in the four relevant cases) as that workload compared to the workload in the face-to-face environment. Three researchers reported a lesser workload in the online environment, while the fourth reported a comparable workload. Researchers who directly compared their online to their faceto-face teaching experiences reported that while the time spent teaching online was not actually greater, the "chunking" or flow of tasks online was quite different, often resulting in a sense of less productive time available for other professional responsibilities. For example, the common expectation that faculty members respond to student messages several times daily meant that the uninterrupted time-spans that many faculty members view as necessary for research and professional writing no longer existed; rather they were "chopped up" into shorter and, in effect, less-productive spans of time.

Although not all such identified challenges were overcome, all of the researchers reported that their work resulted in identification of various strategies that they themselves were implementing to decrease the workload and/or that would be appropriate for the Penn State World Campus Instructional Design \& Development unit to implement as courses are designed or re-designed. Additionally, identification of the factors and interplay of factors that contribute to the perception of greater workload has provided useful information on which to base institutional support of and expectations for faculty members teaching online. Objective 2 was met by supporting faculty members in a research-to-practice activity that resulted in both improved pedagogical and/or technological strategies (which in many cases could be immediately implemented) and contributions to the larger knowledge and practice base made through publications and conference presentations.

\section{B. Project Impact and Sustainability}

The impact of this project has extended from the faculty researchers themselves, to the World Campus Instructional Design \& Development unit, to the larger field as a whole. The faculty members' better understanding of their environment has led to identification of tools and strategies that they are using to enhance their online pedagogy. This knowledge also has been shared with the Penn State World Campus Instructional Design \& Development unit, which is using the new insights and tools to help faculty members in other programs to improve their experiences and satisfaction. Four researchers have disseminated their findings through national and international conference presentations, and the project coordinator presented the results of the project as a whole at the 2003 Outreach Scholarship Conference. One researcher has had an article based on findings published and two others have had articles accepted for publication. Finally, the results of the project were broadly disseminated through submission of the project description to the Sloan-C Effective Practice Web site in the Faculty Satisfaction category. On the basis of this submission the project won the 2003 Sloan-C Effective Practice award in that category. The project team also received the 2004 ADEC (American Distance Education Consortium) Bill Murphy Barrier Buster Award, which recognizes an individual, team, or institution for reducing or eliminating barriers to distance education at the institutional, state, or multi-state level.

This project was not designed as an ongoing endeavor. However, the relatively simple design and low investment necessary to implement the project could make it an appropriate model for investigating other areas of interest related to the faculty experience in ALNs. 


\section{CONCLUSIONS}

This project resulted in contributions both to our knowledge of the online faculty experience and to faculty satisfaction. The findings of the research studies suggest that the interconnectedness of goals and objectives makes dealing with problems such as workload management challenging. For example, achieving the goal of high levels of interaction is often accomplished by implementing tools and strategies that impose a higher workload on faculty. On the other hand, these studies have also shown that workload in the online environment is a variable dependent on a number of factors, many of which are amenable to intervention by either the course designer or the faculty member. In relation to faculty satisfaction, the project provided the opportunity for faculty members to contribute to the knowledge base and improved practice in ways that are recognized and rewarded by the traditional institutional reward system. Finally, the experience of the research team suggests that a model of small faculty research studies, whether supported by an external grant or by institutional research funds, represents an effective and easily replicable approach to examining and addressing the challenges and opportunities of online teaching and learning.

\section{REFERENCES}

1. Frederickson, E., A. Pickett, K. Swan, W. Pelz, and P. Shea. Factors Influencing Faculty Satisfaction with Asynchronous Teaching and Learning in the SUNY Learning Network. In Bourne, J. and Moore, J. (eds.), Online Education: Learning Effectiveness and Faculty Satisfaction, 239-270. Sloan-C: Needham, MA, 1999.

2. Hartman, J., and B. Truman-Davis. Factors Relating to the Satisfaction of Faculty Teaching Online Courses at the University of Central Florida. In Bourne, J. and Moore, J. (eds.), Online Education Volume 2: Learning Effectiveness, Faculty Satisfaction, and Cost Effectiveness, 109-128. Sloan-C: Needham, MA, 2001.

3. National Education Association. A Survey of Traditional and Distance Learning Higher Education Members. Washington D.C., 2000. Online: http://www.nea.org/he/abouthe/dlstudy.pdf.

4. Thompson, M. Faculty Satisfaction in Penn State’s World Campus. In Bourne, J. and Moore, J. (eds.), Online Education Volume 2: Learning Effectiveness, Faculty Satisfaction, and Cost Effectiveness, 129-144. Sloan-C: Needham, MA, 2001.

5. Thompson, M. Faculty Satisfaction in the Online Teaching and Learning Environment. In Bourne, J. and Moore, J. (eds.), Elements of Quality Online Education: Practice and Direction, 189-212. SloanC: Needham, MA, 2003.

6. DiBiase, D. Is Distance Teaching More Work or Less Work? The American Journal of Distance Education 14(3): 6-20, 2000.

7. Clay, M. Development of Training and Support Programs for Distance Education Instructors. Online Journal of Distance Learning Administration 2(3): 1999.

Online: http://www.westga.edu/\%7Edistance/clay23.html.

8. Hislop, G., and M. Atwood. ALN Teaching as Routine Faculty Workload. Journal of Asynchronous Learning Networks 4(3): 2000. Online:

http://www.sloan-c.org/publications/jaln/v4n3/v4n3 hislop.asp.

9. Rockwell, S. K., J. Schauer, S. Fritz, and S. Marx. Incentives and Obstacles Influencing Higher Education Faculty and Administrators to Teach. Online Journal of Distance Learning Administration 3(4): 1999. Online: http://www.westga.edu/ distance/rockwell24.html.

10. Schifter, C. Perception Differences about Participating in Distance Education. Online Journal of Distance Learning Administration, 5(1), 2002.

Online: http://www.westga.edu/\%7Edistance/ojdla/spring51/schifter51.html.

11. Smith, L. Faculty Satisfaction in LEEP: A Web-based Graduate Degree Program in Library and Information Science. In Bourne, J. and Moore, J. (eds.), Online Education Volume 2: Learning Effectiveness, Faculty Satisfaction, and Cost Effectiveness, 87-108. Sloan-C: Needham, MA, 2001. 


\section{ACKNOWLEDGEMENTS}

I would like to acknowledge the Penn State faculty researchers who conducted the research studies in this project:

- Dr. Richard Arteca, Professor of Horticultural Physiology

- David DiBiase, Director of the e-Education Institute and the Peter R. Gould Center for Geography Education and Outreach and Senior Lecturer in Geography

- Dr. Barbara Grabowski, Associate Professor of Education

- Dr. Margaret Lyday, Associate Professor of English

- Dr. J. David Popp, Senior Project Associate in the department of Learning and Performance Systems

- Dr. Al Turgeon, Professor of Turfgrass Management

Their participation has greatly advanced our knowledge of the faculty experience in the online environment. I also gratefully acknowledge the financial support of the Alfred P. Sloan Foundation for this project.

\section{ABOUT THE AUTHOR}

Melody M. Thompson holds a dual appointment at Penn State: in the College of Education as Director of the American Center for the Study of Distance Education (ACSDE) and assistant professor of education and in Outreach as Director of Quality \& Planning for Penn State's World Campus. Her research interests include evaluation of distance education programs, institutional policy related to distance education, quality issues in online education, and the faculty experience in the online environment. She is the editor of DEOSNEWS, the online journal of the American Center for the Study of Distance Education (ACSDE); the editor of the faculty satisfaction pillar of the Sloan-C Effective Practice Web site; is on the editorial board of JALN (Journal of Asynchronous Learning Networks); and is a member of the international steering committee of the Worldwide Universities Network (WUN). 